\title{
The effect of biotin deficiency and dietary protein content on lipogenesis, gluconeogenesis and related enzyme activities in chick liver
}

\author{
BY D. W. BANNISTER, IRIS E. O'NEILL AND C. C. WHITEHEAD \\ Agricultural Research Council's Poultry Research Centre, Roslin, \\ Midlothian EH25 9PS, Scotland
}

(Received 23 August 1982 - Accepted 21 March 1983)

\begin{abstract}
1. Chicks were given biotin-deficient diets containing either suboptimal (low) or supraoptimal (high) concentrations of protein from 1-d-old until they were used during their fourth week of life. The low-protein diet predisposed chicks to develop fatty liver and kidney syndrome and the high-protein diet to develop classical biotin deficiency signs. Two other groups, as controls, received biotin-supplemented rations.

2. Low dietary protein increased lipogenesis by isolated hepatocytes but had little effect on gluconeogenesis compared to high dietary protein.

3. Low dietary protein decreased activities of hepatic isocitrate dehydrogenase $(E C$ 1.1.1.42), fructose1,6-bisphosphatase ( $E C 3.1 .3 .11)$ and glucose-6-phosphatase (EC 3.1.3.9; GP) and increased activities of fatty acid synthase (FAS), citrate cleavage enzyme ( $E C 4.1 .3 .8 ; \mathrm{CCE})$ and malate dehydrogenase (decarboxylating) (EC 1.1.1.39).

4. When biotin deficiency was superimposed, the rate of lipogenesis by isolated hepatocytes (from fed birds) was decreased. Gluconeogenesis from lactate and glycerol was also depressed.

5. Activity of GP was further decreased by biotin deficiency on the low-protein regimen and FAS and CCE were further increased. PK activity was increased by biotin deficiency.
\end{abstract}

Classical biotin deficiency in chicks is expressed as slow growth, poor feathering, perosis and dermatitis (for a review of the condition, see Whitehead, 1978). Although classical biotin deficiency is largely an experimental curiosity, the condition has been reported under commercial circumstances, particularly amongst turkey poults (Robblee \& Clandinin, 1953). A number of years ago an apparently-unrelated condition was described in commercial broiler flocks to which the name fatty liver and kidney syndrome (FLKS) was given (Marthedal \& Velling, 1958). Signs of the syndrome differ from those of classical biotin deficiency: the onset is sudden, the chick becomes progressively weaker and usually dies within $24 \mathrm{~h}$. FLKS affects chicks most commonly between 3 and 5 weeks old and may cause mortality as high as $20 \%$; with experimental diets mortalities of this level are routinely obtainable (Whitehead \& Blair, 1976).

Despite the dissimilarity between the signs of FLKS and biotin deficiency, there is much evidence that the former is responsive to the vitamin (Payne et al. 1974; Whitehead et al. $1976 b$ ) although the incidence is greatly influenced by the major dietary constituents (Blair et al. 1975; Whitehead \& Blair, 1974) and the environment (Whitehead \& Blair, 1974; Whitehead et al. 1975).

The interrelationship between the way biotin deficiency is manifested and major dietary constituents (protein and fat) was clearly demonstrated (Whitehead et al. 1976a) by using a series of biotin-deficient diets with varying protein and fat compositions. These produced a range of expressions from severe classical biotin deficiency signs on a high-protein, high-fat diet to modest signs but almost complete susceptibility to FLKS on a low-protein, low-fat diet.

The observation of an interaction between biotin deficiency and major dietary constituents which radically alters the expression of that deficiency is of scientific interest because it implies that such an interaction distorts either normal development, or control mechanisms 
of major metabolic pathways. At present, no similar phenomenon has been reported in any other species except the turkey, in which FLKS has been induced under laboratory conditions (Whitehead \& Siller, 1983).

In order to learn more about the nature of the interaction at a biochemical level two semi-purified biotin-deficient diets were employed. One contained suboptimum protein (low-protein) whilst the other was supraoptimal (high-protein) because it is known that rations of the former type predispose chicks to FLKS, whereas the latter increases severity of classical deficiency signs (Whitehead et al. 1976a).

\section{MATERIALS AND METHODS \\ Procedure}

The birds were female 1-d-old Ross broilers obtained in groups of about twenty at weekly intervals. On arrival the chicks were assigned at random to one of four separate compartments on the bottom tier of a four-tier heated brooder. Each compartment was supplied with one of the following four diets: (1) biotin-deficient, low-protein (FLKSinducing), (2) supplemented control, (3) biotin-deficient, high-protein (enhanced signs of classical biotin deficiency), (4) supplemented control. The composition of these diets is given in Table 1. After 1 week, the group was moved up to the next tier of the brooder in order to make room for the subsequent group. This procedure was repeated so that the oldest chicks (from week 4 to week 5) were housed on the top tier.

For experiments using isolated hepatocytes and for determination of enzyme activities, only chicks from the top tier were used. For a separate experiment, in which live weight and blood pyruvate carboxylase activity (EC 6.4.1 .1; PC) were measured, the chicks were used when 3 weeks old (see p. 293) and were returned to the brooder thereafter. This

\section{Table 1. Composition $(\mathrm{g} / \mathrm{kg})$ of experimental diets}

(The estimated biotin content of the basal diet was $110 \mu \mathrm{g} / \mathrm{kg}$ of which approximately $40 \mu \mathrm{g}$ was biologically available. The supplemented diet was estimated to contain $240 \mu \mathrm{g}$ biologically-available biotin $/ \mathrm{kg}$ )

\begin{tabular}{|c|c|c|c|c|}
\hline \multirow[b]{2}{*}{ Ingredient } & \multicolumn{4}{|c|}{ Diet no. } \\
\hline & 1 & 2 & 3 & 4 \\
\hline Wheat & 717 & 717 & 717 & 717 \\
\hline Starch & 100 & 100 & - & - \\
\hline Low-vitamin casein ${ }^{*}$ & 30 & 30 & 130 & 130 \\
\hline Isolated soya-bean protein & 100 & 100 & 100 & 100 \\
\hline Limestone & 15 & 15 & 15 & 15 \\
\hline Dicalcium phosphate & 25 & 25 & 25 & 25 \\
\hline Methionine & 3 & 3 & 3 & 3 \\
\hline Lysine & 2 & 2 & 2 & 2 \\
\hline Salt & 3 & 3 & 3 & 3 \\
\hline Vitamin and mineral mix $\dagger$ & 5 & 5 & 5 & 5 \\
\hline Rovimix $\mathrm{H} 2 \ddagger$ & - & 0.01 & - & 0.01 \\
\hline \multicolumn{5}{|l|}{ Chemical analysis } \\
\hline $\mathbf{C P}$ & 192 & 192 & 274 & 274 \\
\hline Metabolizable energy (MJ/kg) & $12 \cdot 6$ & $12 \cdot 6$ & $12 \cdot 8$ & $12 \cdot 8$ \\
\hline
\end{tabular}

$\mathrm{CP}$, crude protein (nitrogen $\times 6 \cdot 25$ ).

* FPD 950; Food Production Developments Ltd, London.

$\uparrow$ Supplied (mg/kg diet): retinol 2, cholecalferol $20 \mu \mathrm{g}, \alpha$-tocopherol 17, menadione $1 \cdot 3$, thiamin 16, riboflavin 4 , nicotinic acid 28 , pantothenic acid 10 , pyridoxine 9 , folic acid 5 , choline $0.8 \mathrm{~g}$, cyanocobalamin $40 \mu \mathrm{g}$, copper $3 \cdot 5$, iodide $0 \cdot 4$, iron 80 , magnesium 300 , manganese 100 , zinc 50 .

$\ddagger$ Containing $20 \mathrm{~g}$ D-biotin/kg; Roche Products Ltd, Dunstable. 
procedure was chosen because enzyme activity is high at this age (Whitehead \& Bannister, 1978) and it was assumed that they would recover in the following 7-14 d.

Thus, the chicks were maintained at a density of five or six per compartment until their fifth week. In those experiments where the effect of starvation was to be studied they were removed to a separate compartment and deprived of food for a period of 18-24 $\mathrm{h}$. Water was available at all times.

Individual experiments were replicated using chicks from several groups.

\section{Preparation of samples}

Blood was withdrawn into a heparinized syringe for determination of PC activity, which was performed on 3-week-old birds that were weighed at the same time.

For determination of enzyme activities, chicks were killed by cervical dislocation and portions of liver removed, homogenized in the appropriate buffer and assayed by the methods described below. A sample of liver was taken at the same time for determination of wet weight: dry weight.

In order to minimize post-mortem changes in activity, enzyme assays were divided into small groups such that the liver samples could be processed quickly.

Isolated hepatocytes were prepared as described previously (Bannister \& O'Neill, 1981).

\section{Enzyme assays}

Blood PC activity was measured by the method of Bannister \& Whitehead (1976).

Enzymes associated with lipogenesis. Fatty acid synthase (FAS) was assayed according to Arslanian \& Wakil (1975) in the supernatant fraction $\left(100000 \mathrm{~g}\right.$ for $1 \mathrm{~h}$ at $\left.4^{\circ}\right)$ from a

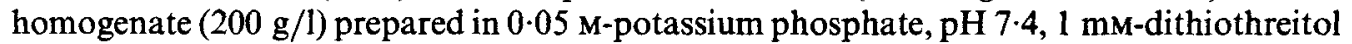
(DTT) and $1 \mathrm{~mm}$-EDTA. Malate dehydrogenase (decarboxylating) $(E C$ 1 1 1 1 1.39; $\mathrm{MDH})$ was assayed according to Wise \& Ball (1964) as described previously (Whitehead et al. 1978). Isocitrate dehydrogenase $(E C 1.1 .1 .42 ; \mathrm{IDH})$ was assayed according to Balnave \& Pearce (1969) except that the homogenate $(200 \mathrm{~g} / \mathrm{l})$ prepared in $0.1 \mathrm{M}$-potassium phosphate, $7 \mathrm{~mm}$-2-mercaptoethanol, $\mathrm{pH} 7 \cdot 0$, was centrifuged for $2 \mathrm{~min}$ in a Beckman Microfuge (approximately $12000 \mathrm{~g}$ ) at room temperature. Citrate cleavage enzyme (EC 4.1.3.8; CCE) was assayed according to Osterlund \& Bridger (1977) in the supernatant fraction $\left(100000 \mathrm{~g}\right.$ for $30 \mathrm{~min}$ at $\left.2^{\circ}\right)$ from a homogenate $(250 \mathrm{~g} / \mathrm{l})$ prepared in $0.25 \mathrm{M}$-sucrose, $0.05 \mathrm{M}$-potassium phosphate, $0.05 \mathrm{M}$-sodium fluoride, $2.5 \mathrm{~mm}$-DTT and $2.5 \mathrm{~mm}$-EDTA, pH $7 \cdot 0$.

Enzymes associated with gluconeogenesis. Phosphoenolpyruvate carboxykinase (EC 4.1.1.32; PEPCK) was assayed according to Seubert \& Huth (1965) as described by Bannister \& O'Neill (1981). Fructose-1,6-bisphosphatase (EC 3 1 . 3 .11;FBP) was measured according to Wallace $\&$ Newsholme (1967) in the supernatant fraction (100000 $\mathrm{g}$ for $1 \mathrm{~h}$ at $4^{\circ}$ ) from a homogenate $(25 \mathrm{~g} / 1)$ prepared in $0.02 \mathrm{M}$-Tris buffer (adjusted to $\mathrm{pH} 8.0$ at $4^{\circ}$ with hydrochloric acid), 2 mM-magnesium sulphate and $0 \cdot 1 \mathrm{~mm}-\mathrm{EDTA}$. Glucose-6phosphatase (EC 3 1.3.9; GP) was assayed according to Harper (1963).

Enzymes associated with glycolysis. Phosphofructokinase (EC 2.7.1.11; PFK) was assayed at subsaturating $(0.4 \mathrm{mM})$ and saturating $(10 \mathrm{mM})$ concentrations of fructose6-phosphate according to Clarke et al. (1979). Pyruvate kinase (EC 2.7.1.40; PK) was also assayed according to Clarke et al. (1979), at saturating (6.6 mM) phosphoenolpyruvate concentration in the absence and presence of $100 \mu \mathrm{M}$-fructose-1,6-bisphosphate. The pyruvate dehydrogenase complex (PDH) was assayed according to Hinman \& Blass (1981) as adapted to chick liver (Bannister, 1982). The homogenizing medium included $0.05 \mathrm{M}-\mathrm{NaF}$ to reduce phosphatase-mediated induction of activity. In this case, the mitochondrial pellets were frozen in liquid nitrogen and stored at $-70^{\circ}$.

All assays were performed at $40^{\circ}$ with the exception of $\mathrm{PDH}$ which was assayed at $25^{\circ}$. 
Gluconeogenesis and lipogenesis by isolated hepatocytes. The rates of gluconeogenesis from fructose, glycerol and lactate were determined. Each precursor was present at an initial concentration of $10 \mathrm{~mm}$ and incubations, in quadruplicate, were performed for $30 \mathrm{~min}$ at $40^{\circ}$. Glucose in the medium was assayed by an automated version of the method of Huggett \& Nixon (1957) and corrected by subtraction of values for incubations carried out in the absence of precursor.

Lipogenesis was measured by incorporation of $\left[\mathrm{U}^{-14} \mathrm{C}\right]$ lactate into the total lipid fraction using the same conditions as for gluconeogenesis. In this instance, each incubation flask contained $5 \mathrm{~mm}$-lactate and $7.4 \mathrm{KBq}$ radioactivity. Total lipids were extracted by the method of Folch et al. (1957).

Presentation of results. All values are presented as the means with their standard errors for the number of observations given in parentheses and statistical differences (given in the text) were determined by analysis of variance.

Chemicals. All chemicals were of analytical grade and were used as supplied (British Drug Houses, Poole, Dorset). Purified enzymes, coenzymes and metabolites were obtained either from Boehringer Corporation (London) Ltd or from Sigma (UK) Ltd. [U- ${ }^{14}$ C]lactate was purchased from Amersham International (Buckinghamshire).

\section{RESULTS}

Live weight and blood PC are indicators of biotin status (Whitehead \& Bannister, 1978, 1981); values for these factors together with hepatic wet weight:dry weight values, which were collected during determination of enzyme activities are given in Table 2 . Live weight at 3 weeks was significantly increased by high-protein diets (diets 3 and $4 ; P<0.05$ ) and also by inclusion of biotin (diets 2 and $4 ; P<0.001$ ).

Blood PC was significantly increased by added biotin $(P<0.001)$ although the effect of high protein in reducing activity fell short of statistical significance.

Both of these observations are consistent with earlier findings that high-protein diets increase the severity of classical biotin deficiency (Whitehead et al. 1976a; Whitehead \& Bannister, 1981).

The values for liver wet weight:dry weight showed an interaction between biotin, protein

Table 2. Live weight, blood pyruvate carboxylase (EC 6.4.1.1;PC) activity and liver wet weight:dry weight in chicks given low-and high-protein, biotin-deficient diets

(Diets 1 and 3 were low- and high-protein respectively and both were biotin-deficient. Complete compositions are given in Table 1. Results are given as mean values with their standard errors for no. of observations shown in parentheses. Statistical differences were calculated by analysis of variance and are given in the text)

\begin{tabular}{|c|c|c|c|c|c|c|c|c|}
\hline \multirow{3}{*}{$\begin{array}{l}\text { Diet } \\
\text { no. }\end{array}$} & \multirow{2}{*}{\multicolumn{2}{|c|}{$\begin{array}{l}\text { Live wt at } \\
3 \text { weeks (g) }\end{array}$}} & \multirow{2}{*}{\multicolumn{2}{|c|}{$\begin{array}{c}\text { Blood PC } \\
\text { (nmol } \mathrm{CO}_{2} \text { incorporated } \\
/ \mathrm{ml} \text { per } \mathrm{h} \text { ) }\end{array}$}} & \multicolumn{4}{|c|}{ Liver wet wt: dry wt } \\
\hline & & & & & \multicolumn{2}{|c|}{ Fed } & \multicolumn{2}{|c|}{ Starved (18-24 h) } \\
\hline & Mean & $\mathrm{SE}$ & Mean & $\mathbf{S E}$ & Mean & SE & Mean & $\mathbf{S E}$ \\
\hline 1 & 325 & $10(20)$ & 425 & $43(20)$ & 3.86 & $0.05(24)$ & $3 \cdot 61$ & $0.07(21)$ \\
\hline $2^{*}$ & 354 & $8(20)$ & 615 & $55(20)$ & 3.52 & $0.07(21)$ & 3.87 & $0.04(24)$ \\
\hline 3 & 330 & $12(20)$ & 323 & $32(20)$ & $3 \cdot 78$ & $0.04(22)$ & $3 \cdot 80$ & $0.03(25)$ \\
\hline $4^{*}$ & 396 & $10(20)$ & 579 & $59(20)$ & $3 \cdot 58$ & $0.05(17)$ & $3 \cdot 76$ & $0.04(22)$ \\
\hline
\end{tabular}

* Biotin-supplemented control diets. 
Table 3. Incorporation of $\left[U^{-14} \mathrm{C}\right]$ lactate into total lipids by isolated hepatocytes from chicks given low- and high-protein, biotin-deficient diets

(Diets 1 and 3 were low- and high-protein respectively and both were biotin-deficient. Complete compositions are given in Table 1 . Isolated hepatocytes were incubated, in quadruplicate, in the presence of $5 \mathrm{~mm}$-lactate containing $7.4 \mathrm{KBq}$ radioactivity, for $30 \mathrm{~min}$ at $40^{\circ}$. Total lipid was extracted by the method of Folch et al. (1957). Results are given as mean values with their standard errors for four observations. Statistical differences were calculated by analysis of variance and are given in the text)

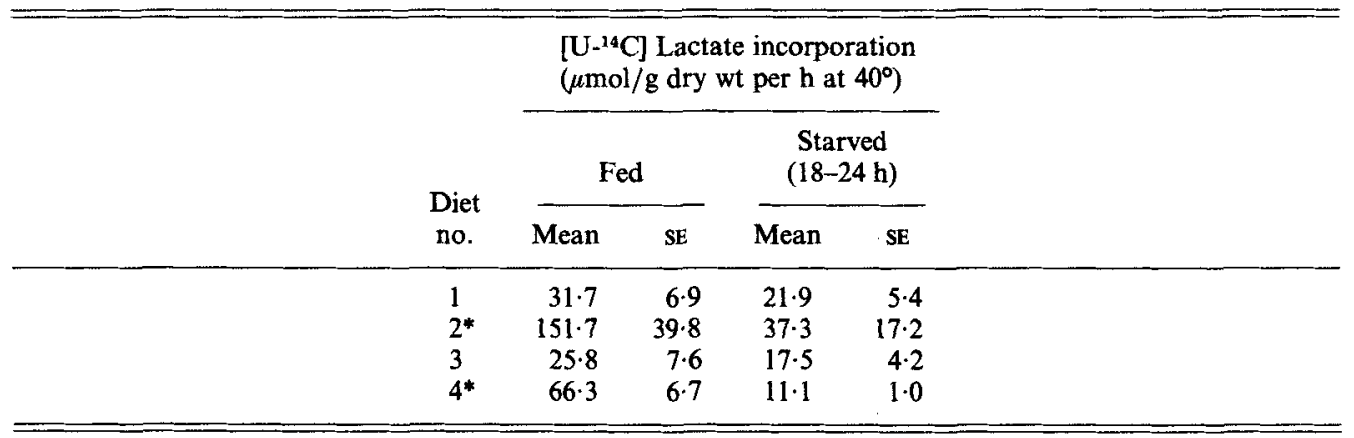

* Biotin-supplemented control diets.

Table 4. Gluconeogenesis from fructose, glycerol and lactate by isolated hepatocytes from chicks given low- and high-protein, biotin-deficient diets

(Diets 1 and 3 were low- and high-protein respectively and both were biotin-deficient. Complete compositions are given in Table 1. Isolated hepatocytes were incubated, in quadruplicate, in the presence of the appropriate precursor for $30 \mathrm{~min}$ at $40^{\circ}$. Correction was made for glucose released in the absence of precursor. Results are given as mean values with their standard errors for no. of observations shown in parentheses. Statistical differences were calculated by analysis of variance and are given in the text)

\begin{tabular}{|c|c|c|c|c|c|}
\hline \multirow[b]{3}{*}{ Substrate } & \multirow{3}{*}{$\begin{array}{c}\text { Diet } \\
\text { no. }\end{array}$} & \multicolumn{4}{|c|}{ Glucose $\left(\mu \mathrm{mol} / \mathrm{g}\right.$ dry wt per h at $\left.40^{\circ}\right)$} \\
\hline & & \multicolumn{2}{|c|}{ Fed } & \multicolumn{2}{|c|}{ Starved $(18-24 \mathrm{~h})$} \\
\hline & & Mean & $\mathbf{S E}$ & Mean & SE \\
\hline \multicolumn{6}{|l|}{ Fructose (4) } \\
\hline & 1 & 225 & 37 & 328 & 41 \\
\hline & $2^{*}$ & 150 & 41 & 414 & 97 \\
\hline & 3 & 96 & 25 & 406 & 49 \\
\hline & $4^{*}$ & 105 & 17 & 388 & $27(5)$ \\
\hline \multicolumn{6}{|l|}{ Glycerol (4) } \\
\hline & 1 & 13 & 5 & 47 & 10 \\
\hline & $2 *$ & 20 & 6 & 64 & 6 \\
\hline & 3 & 21 & 16 & 55 & 5 \\
\hline & $4^{*}$ & 32 & 5 & 72 & $4(5)$ \\
\hline \multicolumn{6}{|l|}{ Lactate (4) } \\
\hline & 1 & 21 & 4 & 201 & 59 \\
\hline & $2^{*}$ & 133 & 42 & 573 & 140 \\
\hline & 3 & 3 & 3 & 257 & 21 \\
\hline & $4^{*}$ & 98 & 24 & 478 & $58(5)$ \\
\hline
\end{tabular}

* Biotin-supplemented control diets. 
Table 5. Activities ( $m m o l / g$ dry wt per $h$ at $40^{\circ}$ ) of lipogenic enzymes in the livers of chicks given low- and high-protein, biotin-deficient diets

(Diets 1 and 3 were low- and high-protein respectively and both were biotin-deficient. Complete compositions are given in Table 1. Activities were measured in fresh tissue by the techniques described on p. 293. Results are given as mean values with their standard errors for no. of observations in parentheses. Statistical differences were calculated by analysis of variance and are given in the text)

\begin{tabular}{|c|c|c|c|c|}
\hline \multirow{2}{*}{$\begin{array}{c}\text { Diet } \\
\text { no. }\end{array}$} & \multicolumn{2}{|c|}{ Fed } & \multicolumn{2}{|c|}{ Starved $(18-24$ h) } \\
\hline & Mean & SE & Mean & $\mathrm{SE}$ \\
\hline \multicolumn{5}{|c|}{ Fatty acid synthase } \\
\hline 1 & $5 \cdot 56$ & $1.62(6)$ & 1.47 & $0.24(6)$ \\
\hline $2^{*}$ & $2 \cdot 09$ & $0.47(7)$ & 0.76 & $0 \cdot 10(7)$ \\
\hline 3 & $2 \cdot 40$ & $0.48(5)$ & $1 \cdot 08$ & $0 \cdot 10(7)$ \\
\hline $4^{*}$ & $2 \cdot 21$ & $0.31(5)$ & $1 \cdot 15$ & $0.17(6)$ \\
\hline \multicolumn{5}{|c|}{ Citrate cleavage enzyme (EC 4.1 .3 .8$)$} \\
\hline 1 & 16.95 & $1.77(6)$ & $15 \cdot 00$ & $1.65(5)$ \\
\hline $2 *$ & $12 \cdot 52$ & $1.42(6)$ & 12.09 & $1 \cdot 19(6)$ \\
\hline 3 & $10 \cdot 29$ & $1.73(5)$ & $9 \cdot 78$ & $0.80(5)$ \\
\hline $4^{*}$ & 11.43 & $1.23(5)$ & $10 \cdot 40$ & $0 \cdot 77(6)$ \\
\hline \multicolumn{5}{|c|}{ Malate dehydrogenase (decarboxylating) (EC 1.1 .1 .39 ) } \\
\hline 1 & $21 \cdot 41$ & $2 \cdot 40(6)$ & 17.84 & $3 \cdot 18(6)$ \\
\hline $2^{*}$ & $20 \cdot 91$ & $1.67(6)$ & $21 \cdot 37$ & $3 \cdot 70(7)$ \\
\hline 3 & $18 \cdot 70$ & $2 \cdot 75(5)$ & $11 \cdot 23$ & $1.53(7)$ \\
\hline $4^{*}$ & $19 \cdot 35$ & $2 \cdot 70(5)$ & $9 \cdot 36$ & $1 \cdot 41(6)$ \\
\hline \multicolumn{5}{|c|}{ Isocitrate dehydrogenase $(E C 1.1 .1 .42)$} \\
\hline 1 & 15.41 & $3 \cdot 38(7)$ & 17.22 & $1.62(7)$ \\
\hline $2^{*}$ & $16 \cdot 16$ & $2 \cdot 60(6)$ & $24 \cdot 43$ & $2 \cdot 17(6)$ \\
\hline 3 & $24 \cdot 23$ & $3 \cdot 36(6)$ & $27 \cdot 24$ & $4 \cdot 25(7)$ \\
\hline $4^{*}$ & 26.00 & $1 \cdot 38(6)$ & 22.89 & $3 \cdot 18(6)$ \\
\hline
\end{tabular}

* Biotin-supplemented control diets.

and starvation $(P<0 \cdot 01)$ which probably reflects a variety of responses to the different conditions. Livers from fed, biotin-deficient chicks had a higher water content than their controls but the reason is not clear. Chicks given the biotin-supplemented diets increased their hepatic water content on starvation, presumably due to mobilization of glycogen, triglyceride and protein. Chicks given diet 1, however, exhibited the opposite trend ( $P<0.05$, Student's $t$ test), which may indicate accumulation of triglyceride as is believed to occur during development of FLKS (Bannister, 1979).

Lipogenesis by isolated hepatocytes. It is known that increasing dietary protein decreases avian hepatic lipogenesis (Yeh \& Leveille, 1969). The in vitro technique used here confirms this effect by demonstrating a significant $(P<0.05)$ decrease in lipogenesis by hepatocytes from chicks given the high-protein diets (Table 3 ). The effect of biotin supplementation was to increase significantly $(P<0.01)$ lipogenesis by hepatocytes from fed chicks at both protein levels. Starvation, which reduced lipogenesis, also abolished the effect of biotin.

Gluconeogenesis by isolated hepatocytes. The hepatocytes exhibited similar properties to those reported previously (Bannister \& O'Neill, 1981) in that lactate and fructose were good precursors whereas glycerol was poor (Table 4).

Fructose. Neither biotin supplementation nor the level of dietary protein had any effect on gluconeogenesis from this precursor. Starvation, however, significantly $(P<0.001)$ increased the rate.

Glycerol. There was no difference in the rate of gluconeogenesis from glycerol between 
Table 6. Activities (mmol/g dry wt per $h$ at $40^{\circ}$ ) of gluconeogenic enzymes in the livers of chicks given low- and high-protein, biotin-deficient diets

(Diets 1 and 3 were low- and-high-protein respectively and both were biotin-deficient. Complete compositions are given in Table 1 . Activities were measured in fresh tissue by the techniques described on p. 293. Results are given as mean values with their standard errors for no. of observations in parentheses. Statistical differences were calculated by analysis of variance and are given in the text)

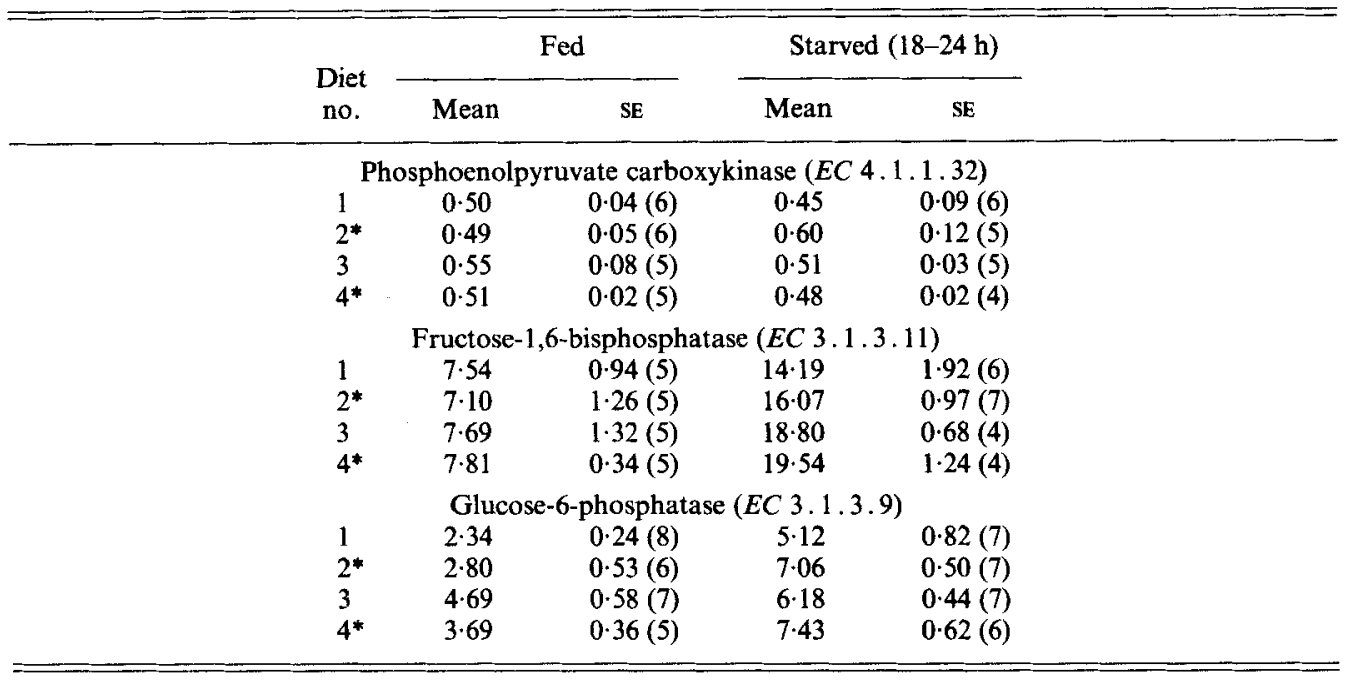

* Biotin-supplemented control diets.

high- and low-protein diets. Biotin supplementation significantly $(P<0.05)$ increased the rate, as did starvation $(P<0.001)$.

Lactate. The response of gluconeogenesis from this precursor was more complex than from the two described previously. Biotin supplementation significantly $(P<0.01)$ increased the rate by hepatocytes from starved chicks but not from fed ones although the rate was considerably higher. High protein significantly $(P<0.05)$ decreased the rate in the presence of biotin supplementation but not in its absence.

Enzyme activities. For ease of presentation, activities have been grouped into three functional categories, lipogenesis (Table 5), gluconeogenesis (Table 6) and glycolysis (Table 7).

Lipogenic enzymes. The activity of FAS was significantly $(P<0.001)$ reduced by starvation. In addition, there was a significant $(P<0.05)$ biotin-protein interaction such that the inclusion of either was associated with decreased enzyme activity. Including both together (diet 4), however, caused no further decrease. The activity of CCE was not reduced by starvation but there was a biotin-protein interaction $(P<0.05)$ similar to that observed with FAS in that additional biotin or protein was associated with lowered enzyme activity but inclusion of both together was without further effect. MDH activity was reduced by starvation $(P<0.05)$. There was no effect attributable to biotin but high dietary protein was again associated with reduced enzyme activity.

There was no evidence for an effect of either starvation or supplementary biotin on IDH activity. In contrast to the other three enzymes in this category, the activity of IDH was significantly $(P<0.01)$ increased as a result of high dietary protein.

Gluconeogenic enzymes. The activity of PEPCK was not affected by starvation or by supplementary biotin or high protein. FBP activity was significantly $(P<0.001)$ increased 
Table 7. Activities (mmol/g dry wt per $h$ at $40^{\circ}$ ) of glycolytic enzymes in the livers of chicks given low- and high-protein, biotin-deficient diets

(Diets 1 and 3 were low- and high-protein respectively and both were biotin-deficient. Complete compositions are given in Table 1. Except for the pyruvate dehydrogenase complex (PDH), activities were measured in fresh tissue by the techniques described on p. 293. Results are given as mean values with their standard errors for no. of observations in parentheses. Statistical differences were calculated by analysis of variance and are given in the text)

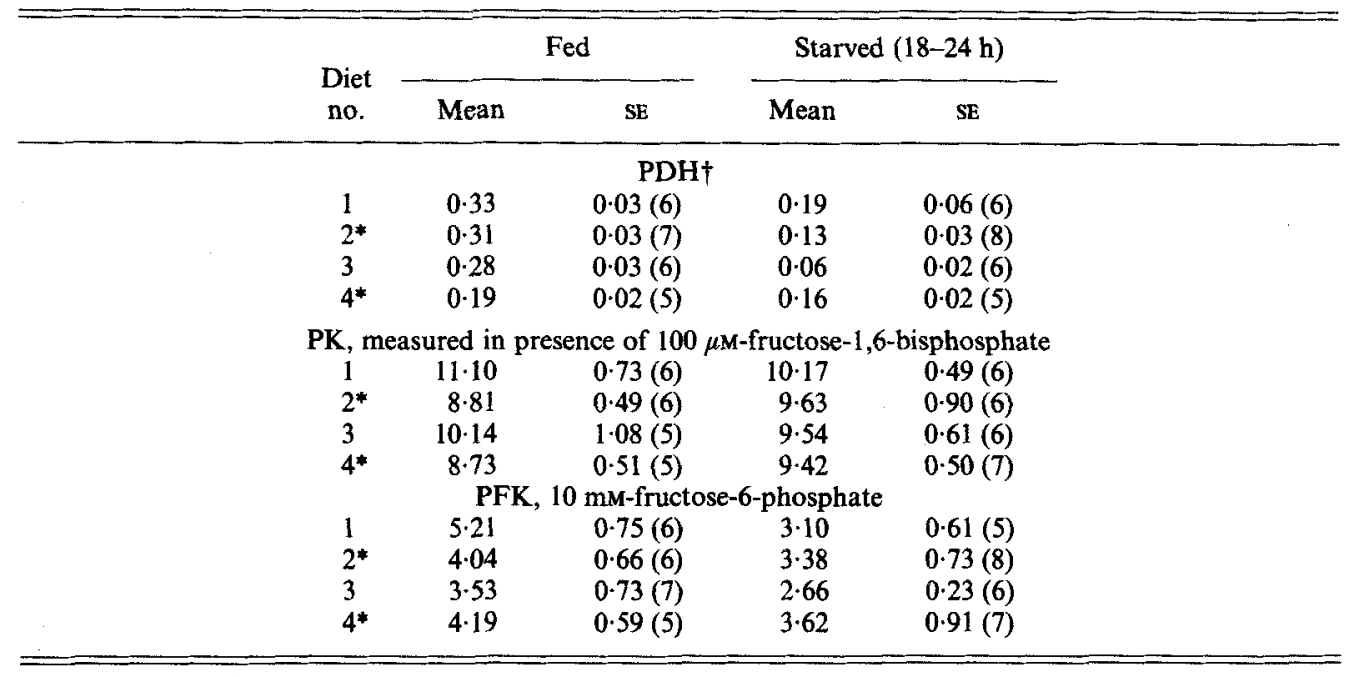

PK, pyruvate kinase (EC 2.7.1 .40); PFK, phosphofructokinase (EC 2.7.1.11).

* Biotin-supplemented control diets.

$\dagger$ Assays performed on mitochondrial pellets which had been stored at $-70^{\circ}$. Rates were measured at $25^{\circ}$.

as a result of starvation and was also increased $(P<0.05)$ by high dietary protein. The activity of GP was also increased $(P<0.01)$ by high protein but in addition there was an interaction between biotin and starvation $(P<0.05)$. Starvation increased activity of the enzyme which was raised further in the presence of supplementary biotin.

Glycolytic enzymes. The response of PDH to dietary protein, biotin and starvation was complex in that there was a significant $(P<0.05)$ interaction between all three variables. PK activity was determined in the presence and absence of its allosteric activator, fructose-1,6-bisphosphate, but because there was no difference in response to the treatments, only the former values are included in Table 7. Activity was not altered as a result of starvation or high dietary protein but was significantly $(P<0.05)$ depressed by supplementary biotin. PFK activity was not affected by either protein or biotin but was lowered $(P<0.05)$ following starvation. Activity at subsaturating concentration of substrate $(0.4 \mathrm{mM})$ showed similar responses to those seen at saturating concentration $(10 \mathrm{mM})$; the values, therefore, have not been included in Table 7.

\section{DISCUSSION}

High-protein diets promote gluconeogenesis whereas those with low protein and high carbohydrate content increase lipogenesis. Much of the evidence reported here supports this general view. For example, lipogenesis by isolated hepatocytes (Table 3) was greater on low-protein diets than on high ones. Furthermore, the gluconeogenic enzymes FBP and GP were raised as a result of feeding high-protein diets. Interestingly, the activity of IDH was also raised as a result of increased protein ingestion, implying that the categorization as a 
lipogenic enzyme (a potential source of NADPH) was not correct. Balnave \& Pearce (1969) noted that changes in the activity of IDH did not always mirror those of other lipogenic enzymes.

Gluconeogenesis by isolated hepatocytes (Table 4), however, did not show any positive response to high dietary protein, as might have been anticipated, and the reasons for this are not clear. One possibility, of course, is that in vitro techniques do not always accurately reflect in vivo status. Since proteins provide amino acids some of which are glucogenic, it would have been logical to test these rather than fructose, glycerol and lactate. However, they are known to be very poor precursors when using chick hepatocytes (Dickson \& Langslow, 1978; Bannister \& O'Neill, 1981). Whilst this phenomenon may be artefactual, there is the possibility, suggested while this work was in progress, that the liver is the site of gluconeogenesis from lactate but the kidneys are the major organs for gluconeogenesis from amino acids (Watford et al. 1981). Such a situation is clearly very different from that in mammals.

When, however, biotin deficiency is superimposed on high- and low-protein intake, the situation becomes more complicated. As classical deficiency develops, PC activity falls more rapidly and to a greater extent than acetyl-CoA carboxylase (ACC) in the livers of rats and chicks (Achuta Murthy \& Mistry, 1972). Whitehead \& Bannister (1981) confirmed the relative susceptibility of the two enzymes to biotin deficiency. Also, they showed that, for a given extent of deficiency, high dietary protein is associated with a relative increase in depression of $\mathrm{ACC}$ and a relative 'sparing' of PC.

At first sight, therefore, it is perhaps surprising that lipogenesis by isolated hepatocytes is reduced by biotin deficiency at both dietary protein levels (Table 3). This becomes clearer when the complex nature of the in vivo regulation of ACC is considered. Recent evidence indicates that the enzyme is subject to a reversible phosphorylation dephosphorlyation mechanism, in which phosphorylation promotes disaggregation of the active polymer (for a review, see Kim, 1979). However, transition between polymeric and monomeric forms of the enzyme is also controlled by metabolite concentration, citrate favouring the active polymer and long-chain acyl-CoA the monomer. McGarry \& Foster (1980) consider this mechanism to be of some importance in regulation, and Meredith \& Lane (1978) have demonstrated that the transition can occur in isolated cells in vitro. Since citrate is both an allosteric activator of the enzyme and (via $\mathrm{CCE}$ ) a substrate, in the present context it is likely that provision of this metabolite is the limiting factor due to the diminished supply of oxaloacetate synthesized by PC.

Gluconeogenesis from lactate was depressed by biotin deficiency (Table 4) which is to be expected since PC catalyses an obligatory step. It was anticipated that there would be little effect on either fructose or glycerol and, whilst this was so with the former, there was significant inhibition with the latter. At present it is not clear why biotin deficiency should decrease gluconeogenesis from glycerol since none of the enzymes directly involved are biotin-dependent.

The effect of biotin deficiency on enzyme activities may be grouped under three headings: (group $a$ ) none: MDH, IDH, PEPCK, FBP, PFK; (group $b$ ) decreased activity: PDH, GP; (group $c$ ) increased activity: FAS, CCE, PK.

Of those in group $a$ IDH and FBP have already been discussed. MDH is believed to be one of the main sources of NADPH for fatty acid synthesis in avian liver and it responded much as expected in that low-protein (lipogenic) diets were associated with increased activity, and starvation with reduced activity. However, this reduction was much more pronounced on diets 3 and 4 than on diets 1 and 2 (Table 5). PEPCK is thought to be one of the rate-controlling enzymes of gluconeogenesis and it is perhaps surprising that no alterations in activity were detected. However, it should be remembered that much of our 
understanding of the regulatory properties of this enzyme is based on studies with the cytosolic form of the enzyme, which is present in mammalian liver (e.g. the rat). In chicken liver the enzyme is exclusively mitochondrial (Utter, 1959) which is one of the main differences in control of gluconeogenesis between birds and mammals (Bannister \& O'Neill, 1981; Watford et al. 1981). PFK, a key enzyme in regulation of glycolysis, behaved as expected, i.e. activity was reduced by starvation.

Of the two enzymes which showed a reduction of activity as a consequence of biotin deficiency (group $b$ ), the behaviour of PDH was complex and difficult to explain. This multi-enzyme complex is subject to regulation by phosphorylation and dephosphorylation and by the ratios, acetyl CoA:CoA and NADH:NAD ${ }^{+}$, which decrease activity as they increase (reviewed by Denton \& Halestrap, 1979). Further information is required before a detailed hypothesis can be offered, although lowered activity would be expected to inhibit lipogenesis because of decreased acetyl CoA synthesis and hence citrate production.

The activity of GP was also reduced by biotin deficiency. This is most clearly seen in results obtained with the low-protein diet (diet 1, Table 6) and which could be significant for the development of FLKS because a similar observation was made in chicks suffering from the condition (Bannister, 1976).

The observation of increased enzyme activity (group $c$ ) in biotin-deficient chicks reported here is not unique, since Balnave \& Jackson (1974) have reported elevated activities of hepatic glutamate-pyruvate transaminase ( $E C$ 2.6.1.2) and oviducal glutamateoxaloacetate transaminase (EC 2.6.1 .1). However, an interesting feature about this group is that FAS and CCE are both lipogenic enzymes. We believe this is the first report of elevated FAS activity resulting from biotin deficiency; however, Balnave et al. (1977) have reported increased activity of CCE in chicks suffering from FLKS.

Although PK was grouped with the glycolytic enzymes (Scrutton \& Utter, 1968), it is also considered to play a role in gluconeogenesis (Feliu et al. 1976, 1977) and fatty acid synthesis (Ochs \& Harris, 1978). In mammals, the liver contains predominantly the L-type isoenzyme which, like ACC and $\mathrm{PDH}$, is subject to regulation by a phosphorylation dephosphorylation mechanism. In addition, allosteric effectors such as fructose-1,6bisphosphate, ATP and alanine are involved in control (reviewed by Denton \& Halestrap, 1979). The position with avian liver is not so clearly understood because the K-type $\left(\mathrm{M}_{2}\right)$ is the predominant species and, apparently, is not regulated by phosphorylation (Ochs $\&$ Harris, 1978). The evidence here indicates a role for PK in lipogenesis.

Concluding remarks. As noted at the beginning of the Discussion, feeding a diet containing suboptimum protein in conjunction with a high carbohydrate content tends to stimulate lipogenesis and reduce gluconeogenesis. These trends are reflected in alterations of activities of at least some of the relevant enzymes. Biotin deficiency in addition to these dietary circumstances appears to exaggerate the change, leading to further elevation of some lipogenic enzymes (FAS, CCE and PK) and reduction of one gluconeogenic enzyme (GP). These are the circumstances in which susceptiblity to FLKS is increased, and our findings are in agreement with the general hypothesis of Hood et al. (1976) that under such circumstances there is an increase in liver size and activities of lipid-synthesizing enzymes. Our results conflict with theirs, however, in indicating a lower rather than greater (than normal) rate of lipogenesis. The probable reasons for the lower rate were discussed earlier.

There are several potential mechanisms by which the activity of an enzyme can be raised. First there is increased synthesis. In rats, however, biotin deficiency lowers the rate of protein synthesis (Dakshinamurti \& Mistry, 1963; Dakshinamurti \& Litvak, 1970) and restoration of the vitamin stimulates the rate of specific proteins from approximately eightfold to not at all (Boeckx \& Dakshinamurti, 1974). This suggests that increased 
synthesis may not be the mechanism. Two other possibilities exist: (1) reduced degradation or (2) altered kinetic properties. Further information on these possibilities is highly desirable and may also throw light on the question why certain enzymes are affected and not others.

Classical biotin deficiency does not involve many changes in activities of biotinindependent liver enzymes (of those included here) when measured in vitro. However, the level of circulating biotin and blood PC activity (Whitehead \& Bannister, 1981) indicate vitamin deprivation of other tissues and it may be speculated that it is this which plays a major part in lowered growth rate and increased severity of dermal lesions. If the speculation is correct then the metabolism and turnover rate of biotin in liver would repay further study.

The authors are grateful to Mr J. Armstrong, Mrs C. E. McNeill, Miss P. Tait and Miss J. R. Thomson for their skilled technical assistance, and to $\mathrm{Mr} \mathrm{D}$. Waddington for his assistance with the statistical analysis.

\section{REFEREN CES}

Achuta Murthy, P. N. \& Mistry, S. P. (1972). Journal of Scientific and Industrial Research 31, 554-563.

Arslanian, M. J. \& Wakil, S. J. (1975). Methods in Enzymology 35B, 59-65.

Balnave, D., Cumming, R. B. \& Sutherland, T. M. (1977). British Journal of Nutrition 38, 319-328.

Balnave, D. \& Jackson, N. (1974). International Journal of Biochemistry 5, 781-786.

Balnave, D. \& Pearce, J. (1969). Comparative Biochemistry and Physiology 29, 539-550.

Bannister, D. W. (1976). Biochemical Journal 156, 167-173.

Bannister, D. W. (1979). International Journal of Biochemistry 10, $193-199$.

Bannister, D. W. (1982). British Poultry Science 23, 555-561.

Bannister, D. W. \& O'Neill, I. E. (1981). International Journal of Biochemistry 13, 437-444.

Bannister, D. W. \& Whitehead, C. C. (1976). International Journal of Biochemistry 7, 619-624.

Blair, R., Whitehead, C. C. \& Teague, P. W. (1975). Research in Veterinary Science 18, 76-81.

Boeckx, R. L. \& Dakshinamurti, K. (1974). Biochemical Journal 140, 549-556.

Clarke, S. D., Watkins, P. A. \& Lane, M. D. (1979). Journal of Lipid Research 20, 974-985.

Dakshinamurti, K. \& Litvak, S. (1970). Journal of Biological Chemistry 245, 5600-5605.

Dakshinamurti, K. \& Mistry, S. P. (1963). Journal of Biological Chemistry 238, 297-301.

Denton, R. M. \& Halestrap, A. P. (1979). Essays in Biochemistry 15, 37-77.

Dickson, A. J. \& Langslow, D. R. (1978). Molecular and Cellular Biochemistry 22, 167-181.

Feliu, J. E., Heu, L. \& Hers, H-G. (1976). Proceedings of the National Academy of Sciences, USA 73, $2762-2766$.

Feliu, J. E., Heu, L. \& Hers, H-G. (1977). European Journal of Biochemistry 81, 609-617.

Folch, J., Lees, M. \& Sloane-Stanley, C. H. (1957). Journal of Biological Chemistry 226, 497-509.

Harper, A. E. (1963). In Methods of Enzymatic Analysis, pp. 788-792 [H. U. Bergmeyer, editor]. London and New York: Academic Press.

Hinman, L. M. \& Blass, J. P. (1981). Journal of Biological Chemistry 256, 6583-6586.

Hood, R. L., Johnson, A. R., Fogerty, A. C. \& Pearson, J. A. (1976). Australian Journal of Biological Sciences 29, 429-441.

Huggett, A. St.G. \& Nixon, D. A. (1957). Biochemical Journal 66, 12 P.

Kim, K-H. (1979). Molecular and Cellular Biochemistry 28, 27-43.

McGarry, J. D. \& Foster, D. W. (1980). Diabetes 29, 236-240.

Marthedal, H. E. \& Velling, G. (1958). Nordiska Veterinarmotet 8, 250-255.

Meredith, M. J. \& Lane, M. D. (1978). Journal of Biological Chemistry 253, 3381-3383.

Ochs, R. S. \& Harris, R. A. (1978). Archives of Biochemistry and Biophysics 190, 193-201.

Osterlund, B. \& Bridger, W. A. (1977). Biochemical and Biophysical Research Communications 76, 1-8.

Payne, C. G., Gilchrist, P., Pearson, J. A. \& Hemsley, L. A. (1974). British Poultry Science 15, 489-498.

Robblee, A. R. \& Clandinin, D. R. (1953). Poultry Science 32, 579-582.

Scrutton, M. C. \& Utter, M. F. (1968). Annual Review of Biochemistry 37, 249-302.

Seubert, W. \& Huth, W. (1965). Biochemische Zeitschrift 343, 176-191.

Utter, M. F. (1959). Annals of the New York Academy of Sciences 72, 451-461.

Wallace, J. C. \& Newsholme, E. A. (1967). Biochemical Journal 104, 378-384.

Watford, M., Hod, Y., Chiao, Y-B., Utter, M. F. \& Hanson, R. W. (1981). Journal of Biological Chemistry 256, 10023-10027.

Whitehead, C. C. (1978). In Handbook Series in Nutrition and Food, sect. E, vol. 2, pp. 65-93. [M. Rechagle, editor]. Florida: CRC Press Inc.

Whitehead, C. C. \& Bannister, D. W. (1978). British Journal of Nutrition 39, 547-556. 
Whitehead, C. C. \& Bannister, D. W. (1981). British Poultry Science 22, 467-472.

Whitehead, C. C., Bannister, D. W. \& Cleland, M. E. (1978). British Journal of Nutrition 40, 221-234.

Whitehead, C. C., Bannister, D. W., Evans, A. J., Siller, W. G. \& Wight, P. A. L. (1976a). British Journal of Nutrition 35, 115-125.

Whitehead, C. C. \& Blair, R. (1974). Research in Veterinary Science 17, 86-90.

Whitehead, C. C. \& Blair, R. (1976). Research in Veterinary Science 21, 141-145.

Whitehead, C. C., Blair, R., Bannister, D. W. \& Evans, A. J. (1975). Research in Veterinary Science 18, 100-104.

Whitehead, C. C., Blair, R., Bannister, D. W., Evans, A. J. \& Jones, R. M. (1976b). Research in Veterinary Science 20, $180-184$.

Whitehead, C. C. \& Siller, W. G. (1983). Research in Veterinary Science 34, 73-76.

Wise, E. M. \& Ball, E. G. (1964). Proceedings of the National Academy of Sciences, USA 52, 1255-1263.

Yeh, Y-Y. \& Leveille, G. A. (1969). Journal of Nutrition 98, 356-366. 